\title{
Menschen machen mobil
}

\section{Liebe Leserinnen und Leser,}

S ie halten unser erstes Buch „Macher der Mobilität" in den Händen. Wie kam es dazu, sind doch ansonsten Fachmagazine unser Metier!? Über die Mobilität der Zukunft, disruptive Ereignisse in der Automobilbranche, regulatorische Veränderungen mit weitreichenden Folgen ist viel geschrieben worden und das natürlich auch zu recht. Es ist offensichtlich, dass sich die Automobilbranche in der wohl schwierigsten Situation seit der Erfindung des Motorwagens befindet. Wir wollen hier dagegen einmal die Menschen in den Vordergrund heben, die sich diesen Herausforderungen stellen. Menschen, die in diesem schwierigen Umfeld mit Ihren Ideen und Visionen die Mobilität von morgen prägen werden.

Natürlich geht das nicht ohne Teams und die entsprechende Infrastruktur, sprich Unternehmen und Kooperationen. Doch die Macher

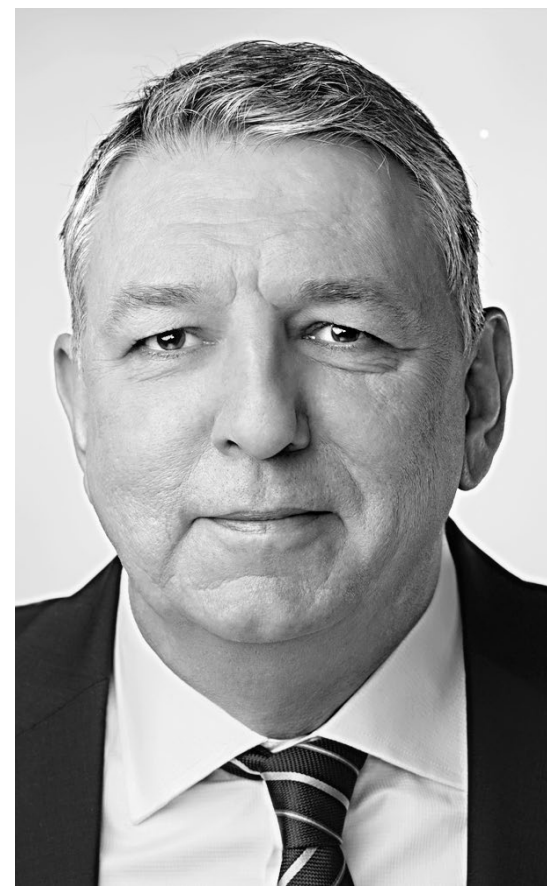

geben die Richtung vor, halten den Kopf hin, wenn etwas schiefgeht und ernten zumindest in der medialen Öffentlichkeit auch die Lorbeeren, wenn es gut läuft. Diese Menschen und ihre Vorstellungen der Zukunft wollen wir Ihnen etwas näherbringen und wir bedanken uns bei allen für die Mitwirkung an diesem Buch.

Besonderen Dank möchte ich an Hildegard Müller aussprechen. Die Präsidentin des VDA hat uns sehr kurzfristig eine Stellungnahme zu den neusten Beschlüssen der EU-Kommission „Fit for $55^{\prime}$ erstellt und die Bedeutung für die Automobilindustrie bewertet. Der einleitende Beitrag "Mobilität für morgen - notwendig, herausfordern, machbar" unseres ATZ-Herausgebers Prof. Peter Gutzmer aus dem Buch „Mobilität der Zukunft",spannt uns den thematischen Rahmen für die Macher der Mobilität.

Ich wünsche Ihnen viel Spaß bei der Lektüre.

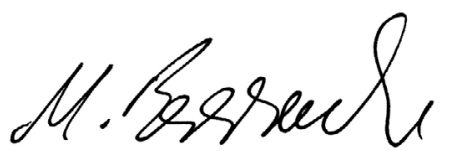

\section{Markus Bereszewski}

Chefredakteur Corporate Solutions 